OPEN ACCESS

1st International e-Conference

on Energies

14 - 31 March 2014

http://sciforum.net/conference/ece-1

Conference Proceedings Paper - Energies „, Whither Energy Conversion? Present Trends, Current Problems and Realistic Future Solutions"

\title{
Voila! A New Measure of Oil Vulnerability for Cities
}

\section{Stacy Rendall ${ }^{1, *}$, Shannon Page ${ }^{2}$ and Susan Krumdieck ${ }^{1}$}

1 Department of Mechanical Engineering, University of Canterbury, Private Bag 4800, Christchurch 8140, New Zealand; E-Mails: stacy.rendall@ canterbury.ac.nz; susan.krumdieck@canterbury.ac.nz

2 Faculty of Environment, Society and Design, Lincoln University, PO Box 85084, Lincoln, 7647, New Zealand; E-Mail: shannon.page@lincoln.ac.nz

* Author to whom correspondence should be addressed; E-Mail: stacy.rendall@ canterbury.ac.nz; Tel.: +64 273040 617; Fax: +64 33642078.

Received: 15 January 2014 / Accepted: 13 March 2014 / Published: 14 March 2014

\begin{abstract}
:
Peak oil, and the ensuing global decline in oil supplies, will adversely affect automobile-dependent personal transport systems. This places users at risk if they are unable to access their activities without oil consumption. This research develops a new measure of oil vulnerability, combining spatial data of vehicle fuel use with a novel transport energy-accessibility metric, the Minimum Energy Transport Activity Access characterisation (METAA), overcoming many of the limitations seen in previous studies. The Vulnerability to Oil: Income, Land-Use and Accessibility (VOILA) assessment identifies vulnerable areas as those where residents might lose access to activities during oil price rises as they can neither afford to spend more on fuel nor adapt their travel patterns to reduce consumption. This new metric allows planners to analyse where, how and why residents are vulnerable. Assessing the oil vulnerability of Christchurch, New Zealand, indicated that although the majority of areas are adaptable, residents in most areas are already spending over $10 \%$ of their income on transport, leaving the less adaptable areas
\end{abstract}


vulnerable. A comparative mapping exercise highlighted the distribution of vulnerability and identified potential mitigation strategies. The research has important implications for urban and transport planning.

Keywords: Oil vulnerability; resilience; accessibility; transport; land-use

\section{Introduction}

Energy, of one form or another, is essential for the transport of people and goods [1]. Historically, this energy was provided by humans, animals or wind. However, the low price and high availability of fossil fuels over the past century has resulted in an almost complete shift to oil as the primary source of energy for transport uses [2,3]. As cities have developed, the low price of fuel, and ease and range of travel made possible by automobiles, has enabled rapid expansion into suburban patterns with low density and dispersed destinations [4,5]. This kind of development, known as sprawl, increases travel distances and is difficult to service with public transport, simultaneously encouraging high levels of vehicle use and increasing energy consumption [6-8]. In consequence, sprawled cities are not only a product of cheap and available fossil fuels, continuous supplies of cheap fossil fuels are required for the transport systems of these urban forms to continue to operate $[9,10]$.

Oil is by its nature a finite resource; there are geological limits upon both the total global supply and rates of production [11]. There is some point at which global oil production will reach a maximum, popularly termed "peak oil", after which time supply will continuously decline [12]. Numerous geologists and researchers have estimated dates at which this maximum will be reached, for example, Mohr [13] identified 26 expert estimates of peak year ranging from 1996 to 2048, while Krumdieck et al. [12] applied a risk analysis approach, building a probability distribution around existing estimates which indicates likely supply under various risk scenarios. This distribution indicates a 50\% probability of peak before 2012 and a 97\% probability of peak before 2020. Regardless of the exact year of maximum production it is apparent that there is a high probability of continuous supply declines from 2020 onward. Benes et al. [11] expect that tightening supply and supply declines in conjunction with predicted levels of demand will result in significant price increases. Consequences for the transportation sector, and particularly private transport, are likely to be significant and will be exacerbated by two factors $[12,14,15]$ :

- transport systems are highly dependent on crude oil, and there are no other energy sources currently available that possess the ability to fill the gap between the amount of energy available into the future and the amount of energy that transport systems require;

- private transport is the most discretionary and most easily reduced of all the uses that society has for oil. It is thus likely to be subject to greater supply reductions than those seen in the overall system. 
The risk of fuel price rises and supply shortfalls to automobile dependent residents in sprawled urban forms is that the ability to travel to activities, such as employment, education and shopping, might be lost. Areas in which residents are vulnerable are those where there are few available alternatives to car use for reaching activities, and where the residents cannot afford to continue current levels of vehicle use.

This research develops a new measure of oil vulnerability, the Vulnerability to Oil: Income, Land-Use and Accessibility (VOILA) assessment. It combines spatial data of household transport energy consumption and fuel cost with a novel transport energy-accessibility metric, the Minimum Energy Transport Activity Access characterisation (METAA).

\section{Oil vulnerability}

The idea of oil vulnerability in cities was first used by Dodson \& Sipe [16] to assess the potential impacts of high oil prices or supply disruptions on urban areas. This study identified that oil vulnerability to price rises and supply disruptions has two components:

- dependence on oil for transport, and

- inability to pay more for transport.

The inability to increase transport spending depends on current levels of income and expenditure, and the value placed on vehicle travel. For simplicity this is often assumed to be largely represented by income. Vulnerable areas are regarded as those in which fuel consumption is high and incomes are low. Oil dependent households with high incomes are not vulnerable, nor are households that are not dependent on oil.

The method does not take mitigation of impacts into account, for example, reducing energy use through mode shifting [16]. Termed the 'vulnerability index for petrol expense rises' (VIPER), Dodson and Sipe used readily available statistical information, from the Australian national census, to derive proxies for both vulnerability components above. Dependence on oil is represented by levels of car ownership and the proportion of residents using a car for the journey to work on census day (JTW); together termed car dependence. Inability to pay more for fuel is represented by a socio-economic index for areas (SEIFA), which comprises numerous demographic and social factors, including household income, education, housing tenure and occupational status [17]. The VIPER index was applied to cities at the geographic level of the census Collection District (CD), each of which contains approximately 200 households [18]. The method assigns every CD a number of points for each of the variables, as shown in Table 1, depending on its percentile rank compared to other CDs in the study area. More vulnerable areas are assigned higher values for each variable. The scores for each variable are summed to produce the final VIPER index, which can have values from zero, representing the least vulnerable area, up to 20. The researchers applied VIPER to three Australian cities: Brisbane, Sydney and Melbourne, with the results showing the relative vulnerability of areas within each city (VIPER cannot be used to directly compare cities to one another). The results indicated lower vulnerability in higher income and central areas, and greater vulnerability in 
lower income areas and outlying centres lacking quality public transport. Vulnerability tended to decrease slightly in the most outlying areas, presumably as these new areas were associated with higher incomes, and along major public transport corridors. A number of similar oil vulnerability studies, in which a composite index is developed by ranking areas within the study boundary, are discussed below and outlined in Table 2.

Table 1. Variable percentile points and weighting scheme used by VIPER

\begin{tabular}{cccc}
\hline \multirow{2}{*}{ Percentile } & \multicolumn{3}{c}{ Value assigned (includes variable weighting) } \\
\cline { 2 - 4 } & SEIFA & Car ownership $\geq 2$ & JTW by car \\
\hline 100 & 0 & 5 & 5 \\
90 & 2 & 4 & 4 \\
75 & 4 & 3 & 3 \\
50 & 6 & 2 & 2 \\
25 & 8 & 1 & 1 \\
10 & 10 & 0 & 0 \\
\hline
\end{tabular}

VIPER was followed by the 'vulnerability assessment for mortgage, petrol and inflation risks and expenditure' (VAMPIRE) index, which was also applied to a number of major Australian cities [18]. VAMPRIE kept the same proxies for oil dependence, but used a combination of household income and mortgage tenure to represent inability to pay more for fuel. Compared to VIPER the results showed a more linear pattern, with greater vulnerability further from central areas, indicating the effects of mortgage tenure on vulnerability.

The use of simple proxies and readily available information in both studies means that computational requirements are low, and the method can be easily applied to other cities and countries. VAMPIRE has since been applied to Hillsborough County, Florida, by Ice [19] and cities and towns in New Zealand by Abley, Krumdieck, \& McDonald [20]. The ease with which the method can be understood has seen it widely discussed and referenced, and it has gained some traction in policy circles [21].

Arico [22] developed a method to assess the relative social vulnerability of Canadian metropolitan areas to oil price rises. This study defined residents aged 15 years and over as vulnerable, due to higher levels of car use, assuming that they will be more directly affected by oil price increases. Vulnerable age groups, JTW and household transport expenditure together represent oil dependence, while incidence of low income population living in private households represents inability to pay more for fuel. This study, with its focus on metropolitan areas, compared 14 Canadian cities to each other, but did not assess the relative vulnerability of different areas within cities. The author found a significant variation between cities, with the most vulnerable city performing poorly in all variables. In many cities increased vulnerability in some variables, such as income, was offset by lower vulnerability in others, such as greater use of public transport. 
Fishman \& Brennan [23] furthered the methodology of Dodson \& Sipe, making use of the Victorian Integrated Survey of Travel and Activity (VISTA) to develop better proxies of oil dependence, although at the lower spatial resolution of Local Government Areas, rather than census Collection Districts. The researchers used weekly fuel use and the modal split of noncar modes for all weekday travel to represent oil dependence, and personal income to represent inability to pay more. The study investigated only the city of Melbourne, Australia. A similar pattern was exhibited to that seen with the VAMPIRE index, with lowest vulnerability found around the central business district and highest vulnerability in fringe areas. However, the lower spatial resolution prevented the identification of local scale effects, such as vulnerability variations related to public transport corridors or fringe areas.

All of the above oil vulnerability indices are produced by ranking areas relative to each other over a number of variables, assigning points depending upon the rank position for each variable, then summing the points. A number of recent studies have developed oil vulnerability metrics that also use measures directly derived from their input variables, rather than ranking the relative performance of areas. These studies are discussed below and summarised in Table 2 .

With the aim of understanding the oil vulnerability implications of master planned estates (MPEs) and non-metropolitan areas, Runting et al. [17] developed an oil vulnerability measure incorporating commute distances and accessibility to public transport. MPEs are large-scale low density suburbs that possess a defined boundary and consistent character, and are controlled by a single developer. The researchers developed a visual classification chart to display the vulnerability findings. Ability to pay more for fuel was displayed on the y-axis, represented by the socio-economic index for areas (SEIFA), as used by VIPER. Oil dependence was displayed on the $\mathrm{x}$-axis, and was represented by a number from 0 to 100 (most dependent), the average of three derived variables:

- Average commuting distance (indexed, 0-100, for all areas relative to largest average distance) - the distance from area to each employment zone weighted by the number of commute trips from the area to the employment zone

- Automobile dependence - average of percentage of dwellings with more than two vehicles and percent JTW by car

- Non-motorised accessibility to public transport - percent of households within active mode distance $(2 \mathrm{~km})$ of a public transport stop

The study investigated the area of South East Queensland, which includes three metropolitan areas, numerous towns, and a large rural area. The researchers incorporated changes over time by comparing vulnerability values for 2001 and 2006, corresponding to consecutive census surveys. The results showed lower vulnerability in metropolitan areas, due to shorter commutes, higher public transport access and higher socio-economic status. Areas containing MPEs were more vulnerable than comparable areas, with high vehicle ownership and use, longer commute distances and a lack of non-motorised public transport access. Over time most MPEs reduced their vulnerability, almost exclusively through increases in socioeconomic advantage. 
Li, Sipe, \& Dodson [24] combined vehicle kilometres of travel (VKT) for work trips, derived from Australian census results, with vehicle fuel efficiency data to calculate commute energy and compared this value to the SEIFA. This allowed them to identify vulnerable areas of high commute energy and low socio-economic advantage in Brisbane. The researchers found that one third of the most disadvantaged suburbs in the study were among the most energy intensive, indicating extreme vulnerability. Unlike previous studies, the researchers did not map a numerical metric, but rather used the distribution of each variable to identify a number of areas of greatest vulnerability. Compared to the VIPER results for Brisbane a number of areas reduced their vulnerability, as the new measure emphasised different facets of the issue.

Lovelace \& Philips [25] developed four metrics to assess different aspects of oil vulnerability for commuter patterns: fuel poverty, proportion of energy use expended on work travel (at both statistical area and individual levels), and a hybrid measure encompassing distance to nearest employment area, proportion JTW by car and commute cost. The metrics were closely correlated, and shared a similar spatial distribution. As the metrics did not expressly assess income or socio-economic deprivation the outputs identified that many areas at risk from high oil prices were not areas traditionally considered in need of support. For example: high income workers living in efficient houses on the outskirts of cities who drive inefficient vehicles, and thus spend a disproportionate amount of their energy budget on commuting. The use of micro-simulation in the calculation of some metrics allowed vulnerability to be compared to individual level characteristics, identifying, for example, that commuter fuel poverty is associated with older travellers. 
Table 2. Summary of existing oil vulnerability studies

\begin{tabular}{|c|c|c|c|}
\hline \multirow{2}{*}{ Authors } & \multirow{2}{*}{$\begin{array}{l}\text { Type of vulnerability } \\
\text { measure }\end{array}$} & \multicolumn{2}{|c|}{ Variables (weighting, if applicable) } \\
\hline & & Oil dependence & Inability to pay more for fuel \\
\hline Dodson \& Sipe [16] & Area-rank composite index & $\begin{array}{l}\text { Households with } \geq 2 \text { cars }(1 / 4) \\
\text { JTW } \operatorname{car}(1 / 4)\end{array}$ & $\operatorname{SEIFA}(1 / 2)$ \\
\hline Arico [22] & Area-rank composite index & $\begin{array}{l}\text { Proportion age } \geq 15(1 / 4) \\
\text { JTW car }(1 / 4) \\
\text { Average transportation expenditure (1/4) }\end{array}$ & Incidence of low income residents $(1 / 4)$ \\
\hline Dodson \& Sipe [18] & Area-rank composite index & $\begin{array}{l}\text { Households with } \geq 2 \text { cars }(1 / 6) \\
\text { JTW } \operatorname{car}(1 / 6)\end{array}$ & $\begin{array}{l}\text { Mortgage or rent/buy scheme (1/3) } \\
\text { Median weekly household income (1/3) }\end{array}$ \\
\hline Fishman \& Brennan [23] & Area-rank composite index & $\begin{array}{l}\text { Weekly fuel use }(1 / 3) \\
\text { Mode split of non-car modes (1/3) }\end{array}$ & Personal income $(1 / 3)$ \\
\hline Runting et al. [17] & $\begin{array}{l}\text { Classification chart (index } \\
\text { versus composite index) }\end{array}$ & $\begin{array}{l}\text { Weighted average car JTW distance }(1 / 3) \\
\text { Households with }>2 \text { cars }(1 / 6) \\
\text { JTW car }(1 / 6) \\
\text { Percent of area households with active mode access } \\
\text { to public transport }(1 / 3)\end{array}$ & SEIFA \\
\hline Li, Sipe, \& Dodson [24] & Area comparison & $\begin{array}{l}\text { Commute energy (derived from JTW VKT and regist } \\
\text { SEIFA }\end{array}$ & ered vehicle fuel efficiency database) \\
\hline Lovelace \& Philips [25] & Series of numerical metrics & $\begin{array}{l}\text { 1. Proportion of people spending more than } 10 \% \text { of } \\
\text { 2. Proportion of energy use expended on work trave } \\
\text { 3. Proportion of individuals spending more than } 10^{\circ} \\
\text { 4. Distance to employment centre, proportion JTW }\end{array}$ & $\begin{array}{l}\text { their income on work travel } \\
0 \text { of their 'energy budget' on work travel } \\
\text { y car and average commute energy cost }\end{array}$ \\
\hline
\end{tabular}




\subsection{Summary of oil vulnerability studies}

One of the goals of the VIPER study was to stimulate international scholarly debate about oil vulnerability [16]. The growing number of oil vulnerability studies are an indication of the shift in attention to the issue as a result of the 2007-2008 oil price spike. Dodson and Sipe noted that data limitations were a particular impediment in the VIPER study, forcing the use of simple proxies and arearanking methods to account for multiple vulnerability variables. Some of the studies that followed have made use of more advanced datasets, but are still constrained by some or all of the following:

- Area-rank and/or indexing methods, which hide real trends in the data and prevent different study areas being compared to one another.

- Assessing only work travel, when other activities such as education, shopping and social visits can attract as many trips employment; see Rendall [26].

- Using proxies to represent the underlying factors that influence vulnerability.

All but one of the current studies assume that the only viable option available to travellers during a fuel price rise is to spend a greater amount of their income on travel. However, it is also possible to adapt by shifting to less fuel-intense modes of travel and selecting activity destinations that may require less travel. The extent to which the travellers in an area can shift modes and change destinations, termed adaptive capacity, is a property of the traveller and the available land-use and transport alternatives [27]. Only Runting et al. [17] take into account the ability of travellers to offset price rises by walking or cycling to public transport. However, they do not consider what destinations might be accessible by the public transport service once accessed, nor accessing activities by active modes.

The objective of this research is to develop an oil vulnerability assessment method that directly compares vulnerability variables, rather than using area-rank or indexes, assesses travel for all purposes, minimises the use of proxy variables and accounts for traveller adaptability.

\section{Method}

This research develops a quantitative oil vulnerability analysis method, called the Vulnerability to Oil: Income, Land-Use and Accessibility (VOILA) assessment. The method minimises the use of proxies in representing vulnerability, making use of the Minimum Energy Travel Activity Access (METAA) characterisation and levels of current fuel use, both described below, and statistical information. It applies a visual charting method, as developed by Runting et al. [17], to explore the two key aspects of oil vulnerability. Similar to previous oil vulnerability metrics, this metric is essentially applicable at the household level, however limited data availability at this level means that the metric is applied to statistical areas.

\subsection{Technical background}

This section outlines the methodology and dataset upon which the new measure of oil vulnerability is based. 


\subsubsection{Minimum energy consumption}

The Minimum Energy Travel Activity Access characterisation (METAA) is an estimation of the minimum transport energy required by households to meet their day-to-day activity requirements [26,28]. The model is summarised here, a full description can be found in Rendall [26]. The method combines an energy-weighted accessibility analysis with aspects of activity modelling. METAA accounts for the resident population, including the ability of people to use different modes and chain trips together, and the frequency with which activities are accessed, all of which are functions of age. The method is spatial, and uses a range of geographical information systems (GIS) data, including the layout of land uses and the design and performance of transport systems.

METAA uses data derived from national household travel survey results for the country under examination. In New Zealand the Household Travel Survey collects trip mode, purpose and duration information over a two-day period [29]. Mode ability is defined as a travel time limit by age group, incorporating the speed at which travellers of different ages are able to travel by each mode. Trip chaining represents the current level of trip chaining undertaken by various age groups. Activity frequency represents the annual trips made by each age group to different activities, such as shopping, employment or education. All activity destination classes contained in the household travel survey are used in the analysis. For each activity the method locates a critical number of opportunities, representing the effects of activity classification as used by household travel surveys; for example, the category Shopping includes grocery stores, book stores, clothing stores, and so on. Each non-employment facility represents one opportunity, while for employment the number of opportunities is represented by the number of employed persons at the facility. Residents within statistical areas are assigned randomly to households using statistical data, this process has two steps:

1. Randomly draw the number of residents for each household in each area without replacement from the data

2. Randomly draw age values for each resident in each area without replacement from the data, assigning to households until the assigned number of residents is matched

The minimum energy calculation is presented in Figure 1 and described below:

1. Calculate travel distance and time by each mode from every origin to the critical number of opportunities for each activity

2. Randomly assign household sizes and resident demography in each area

3. For each household resident determine the minimum energy travel mode for each trip, until the critical number of opportunities is attained, and calculate the specific minimum energy in reaching the activity

4. Sum minimum energy, accounting for opportunities at the destination, activity frequency and trip chaining, for all residents in the household

Modes are assigned through a minimum energy hierarchy, this means that for any destination the resident is able to walk to, walking is the selected mode for that destination. If they are unable to walk, but are able to cycle to the destination, then cycling is the selected mode, and so on. It is assumed that any trip that cannot be made by other modes can be made by car. The random population assignment 
and minimum energy calculation is repeated and the results are averaged. The METAA model calculates a value per household, representing the minimum possible transport energy consumption in Megajoules.

Figure 1. Overview of the METAA minimum energy calculation

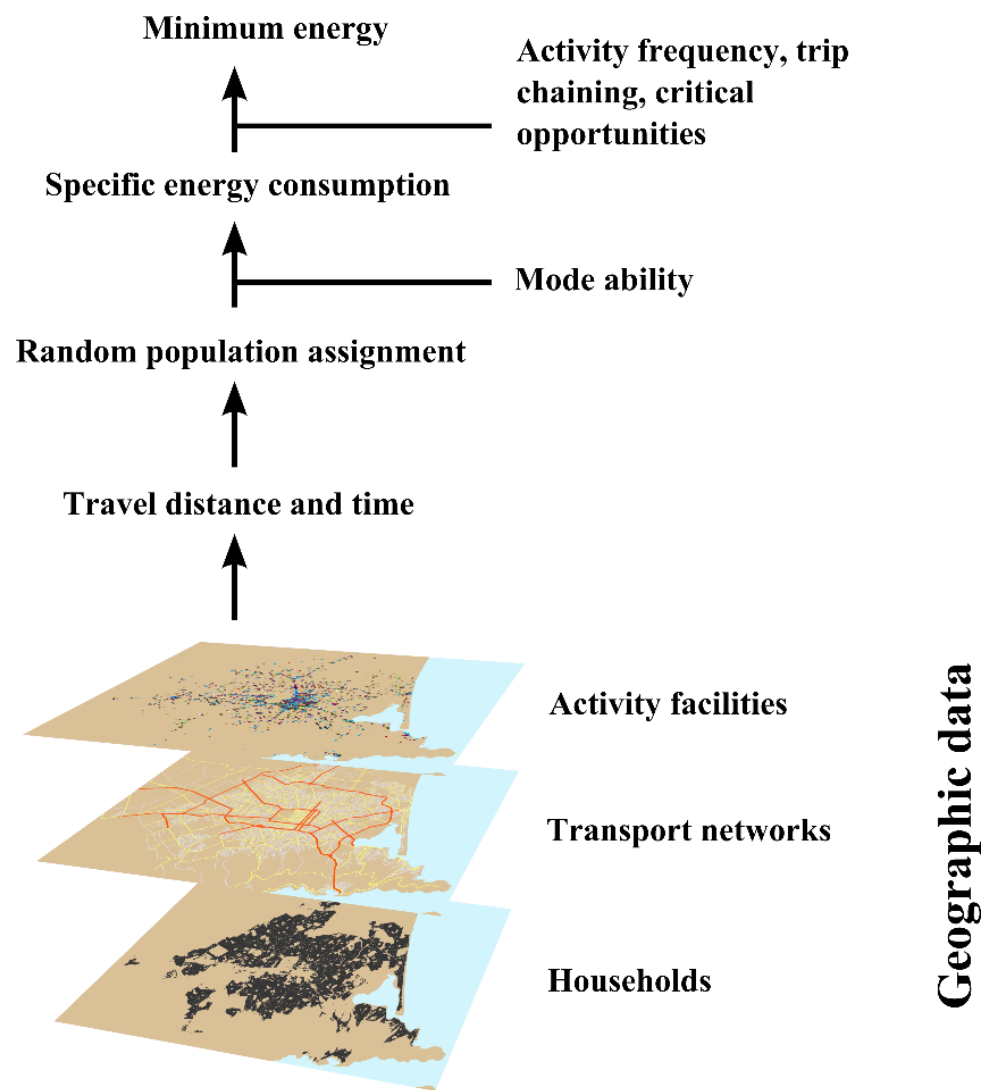

The METAA output does not represent behaviour, but the minimum transport energy that might be consumed by residents in the area as a function of demography, land-uses and transport systems. The difference between current and minimum transport energy consumption can be thought of as the capacity of residents to adapt that is inherent within the urban form.

\subsubsection{Current vehicle energy consumption}

New Zealand law requires that road-going vehicles are regularly inspected for safety at a certified facility. During this inspection the reading on the vehicles odometer is recorded, along with the registered address, and information of fuel type and engine size. The New Zealand Ministry of Transport (MoT) use this database to calculate national travel and fuel consumption statistics [MoT, 30]. This research used the odometer database and vehicle address information to develop a spatial database of private vehicle fuel and energy consumption over 10 years for New Zealand urban areas, at the statisticalunit level. The database can be combined with fuel and travel cost information to estimate overall travel costs. 


\subsection{Theoretical derivation}

In an unconstrained situation people will make choices about the modes they use and which particular set of facilities they travel to. This travel behaviour results in some level of energy consumption. During an oil crisis, which might include price rises or supply shortfalls, travellers will be faced with three choices:

- Maintain current travel by spending more on fuel

- Adapt by changing modes or selecting closer facilities for conducting activities

- Forgo activities

Adaptations for extended fuel crises can include purchasing a more efficient vehicle or moving residential location to be closer to activity facilities, although the ability to afford such measures during a fuel crisis may be limited. The VOILA assessment specifically considers vulnerability to short term fuel price rises, it does not consider long term adaptations.

Activity participation is considered to be essential for all activities, not only for subsistence activities such as employment, education and shopping. This represents the requirement of humans to interact socially and engage in other maintenance activities. Consequently, travellers being forced to forgo any activities during an oil crisis is considered to be a failure of the transport-activity system.

It is proposed that the term oil dependence, as used in earlier studies, actually represents current oil use. Oil dependence is the condition of oil use coupled with an inability to adapt, which was not comprehensively assessed by any of the previous studies.

VOILA proposes two complementary measures that combine to represent oil vulnerability, adaptability and maintainability, as described in the following sections. They represent the ability of travellers to either adapt or maintain travel during fuel price rises.

\subsubsection{Adaptability}

The variable of adaptability is a comparison between current energy consumption and minimum energy consumption. Low adaptability areas are those in which both current and minimum energy consumption are high; adaptable areas have low minimum energy; while areas of low current energy consumption do not need to adapt, as presented in Figure 2. The adaptability space is represented by a triangle, as it is not possible to have greater minimum energy consumption than current energy consumption. Although adaptability is a positive attribute, there is still some level of risk associated with adaptation, hence adaptable households are more vulnerable than households with low energy requirements.

\subsubsection{Maintainability}

The variable of maintainability represents the extent to which travellers are able to spend more on transport. It would ideally be a measure of the amount of money available to the traveller that could be 
used to maintain travel during a crisis. However, such a value is dependent on a wide range of factors, including the presence of dependents and mortgage or rental status, and could not be determined without a large number of assumptions. To reduce complexity maintainability is considered to be a comparison between transport spend and income. The maintainability space is presented in Figure 2, indicating decreased maintainability for areas with higher transport spend and lower income.

Figure 2. Adaptability and maintainability spaces
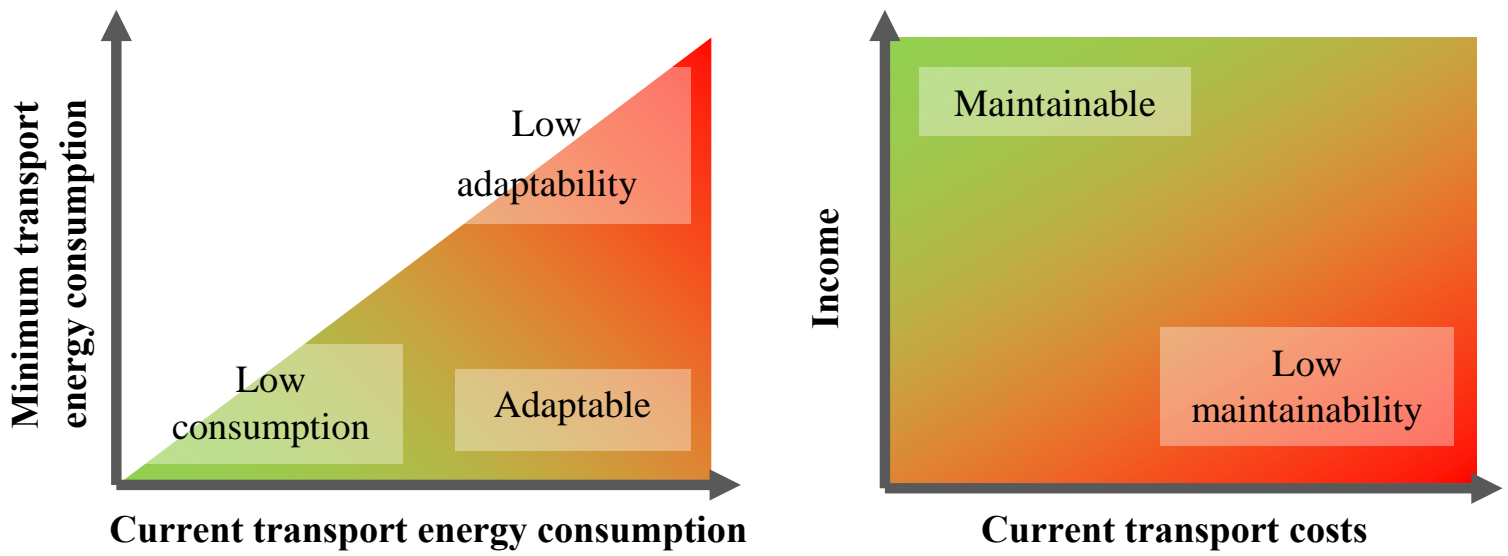

\subsubsection{Vulnerability}

The VOILA method is based upon the idea that a resilient transport system is one in which residents can continue to participate in their activities regardless of constraints upon the system. The method by which activity participation is maintained is less important than the fact that it is maintained. VOILA does not account for the fact that it may not be possible to maintain current travel patterns during an actual supply shortfall at the pump.

The most vulnerable areas are those in which residents can neither adapt nor maintain their current energy consumption, as presented in Figure 3. Although it is intuitive that decreasing adaptability and maintainability will make travellers more vulnerable, it is currently not known how these two variables combine or offset one another, nor the extent to which changes in either will quantitatively affect the ability of residents to endure oil shocks. Future work on the VOILA method will examine these aspects in greater detail and focus on developing a combined quantitative output. For analysis in this paper, maps of the two variables were visually combined to allow identification of vulnerable areas as those with both low adaptability and maintainability. 
Figure 3. Vulnerability space

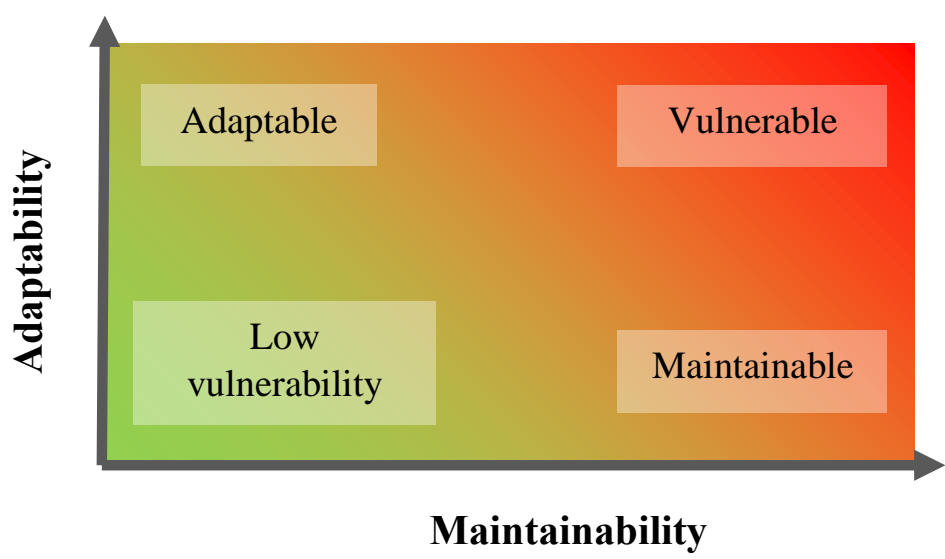

To produce a figure suitable for visual comparison, values for adaptability and maintainability were calculated using the following equations:

$$
\begin{gathered}
\text { adaptability }=\frac{\text { minimum energy }}{\text { current energy }} \\
\text { maintainability }=\frac{\text { transport costs }}{\text { income }}
\end{gathered}
$$

Census units in the study area were then partitioned into three categories for each variable, representing high, medium and low, such that each category contained an equal number of areas. These variables were then simultaneously plotted for all areas, allowing assessment of the relative performance over both variables compared to other areas.

\section{Case Study}

The VOILA method has been applied to the New Zealand city of Christchurch, using data from 2006. A series of earthquakes in 2010/2011 have since drastically altered the city, forcing at least 12,000 residents to move from the eastern suburbs, and the majority of businesses to leave the central business district (CDB) due to extensive damage to buildings, land and services. An overview of Christchurch, circa 2006, is presented in Figure 4. Although Christchurch has a comprehensive bus network, ridership levels are low on most routes and it represents only $4 \%$ of the mode share for all trips [29]. 
Figure 4. Overview of Christchurch

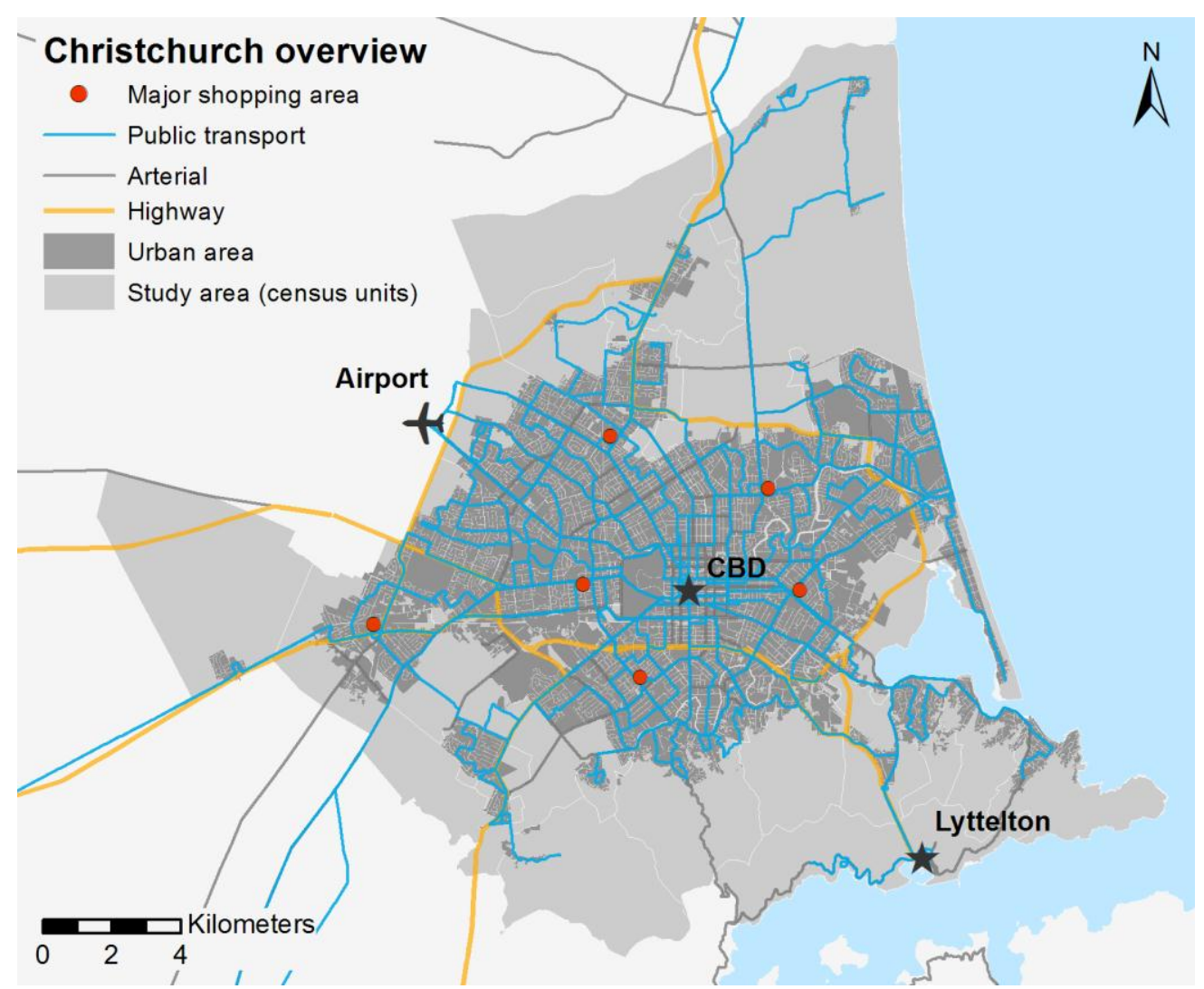

Annual transport costs, input to the VOILA method, are calculated as the sum of fuel costs and include road user charges for diesel vehicles. Statistical level data of public transport use in Christchurch, which would allow public transport costs to be calculated, are unavailable. The prices of fuel and road user charges in 2006 are outlined in Table 3, along with the energy content of each fuel. In the year of 2006 there were no electric vehicles in Christchurch.

Table 3. Travel costs in 2006 and fuel energy content values used in the model

\begin{tabular}{rcc}
\hline Fuel & Cost & $\begin{array}{c}\text { Energy content } \\
(\mathbf{M J} / \mathbf{L})\end{array}$ \\
\hline Petrol & $1.59 \$ / \mathrm{L}^{1}$ & 35 \\
Diesel (Road User Charges) & $1.13 \$ / \mathrm{L}^{2}(+0.31 \$ / \mathrm{km})^{3}$ & 38 \\
Liquid Propane Gas (LPG) & $1.00 \$ / \mathrm{L}$ & 26 \\
\hline
\end{tabular}

The model inputs are presented as a series of maps in Figure 5, all of which are averages over all households in the area, apart from income, which represents the median value. The distribution of

\footnotetext{
${ }^{1}$ Assuming 30\% premium grade and $70 \%$ regular grade petrol. Source: http://www.transport.govt.nz/ourwork/tmif/transportpriceindices/ti005/

${ }^{2}$ Source: http://www.transport.govt.nz/ourwork/tmif/transportpriceindices/ti006/

${ }^{3}$ Source: http://www.transport.govt.nz/ourwork/tmif/transportpriceindices/ti010/
} 
income indicates lower income areas to the south and east of the CBD, with highest income areas to the northwest of the $\mathrm{CBD}$, and on the southern fringes of the city. Annual transport costs and energy consumption largely increase with increasing distance from the CBD, with some exceptions. The METAA minimum energy results for Christchurch indicate residents near the CDB could access all of their activities without travel, as they have a minimum energy of zero. The highest minimum transport energy values are seen on the fringes of the city.

Figure 5. Inputs to the VOILA analysis for Christchurch

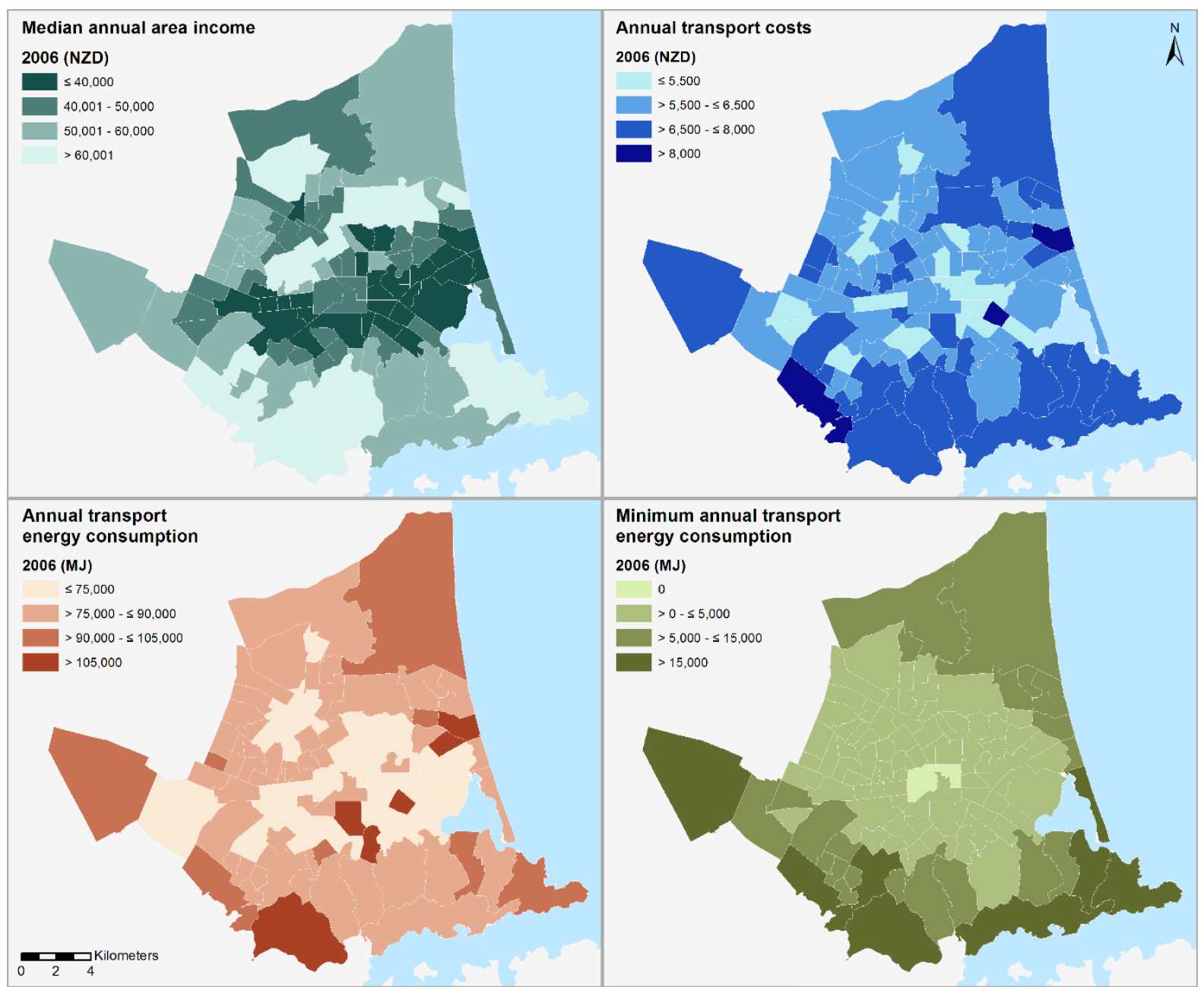

The Christchurch adaptability space is presented in Figure 6, with the line of equal current and minimum energy highlighted. The figure indicates many areas in Christchurch are highly adaptable: the lowest value of current energy consumption is over $55 \mathrm{GJ} / \mathrm{yr}$, but most areas have a minimum energy near zero. A few areas with current energy around $180 \mathrm{GJ} / \mathrm{yr}$ have minimum energy under $10 \mathrm{GJ} / \mathrm{yr}$. Most areas are clustered around 55-100 GJ/yr current energy, however there is a large spread of minimum energy for some areas, with some areas at 20-30 GJ/yr and one area as high as $45 \mathrm{GJ} / \mathrm{yr}$.

The Christchurch maintainability space is presented in Figure 7, annotated with a line showing transport costs equal to $10 \%$ of income, which is commonly used as a definition of commuter fuel poverty [e.g. 25]. The figure indicates a spread in median incomes from $\$ 30,000$ to $\$ 100,000$ and fuel costs ranging from $\$ 4,000$ to $\$ 10,000$. Two areas with the greatest current fuel costs are also near the 
lowest income. The majority of areas have transport costs greater than $10 \%$ of income, and hence might be considered to be in fuel poverty.

Figure 6. Christchurch adaptability space (2006), equal current and minimum energy shown

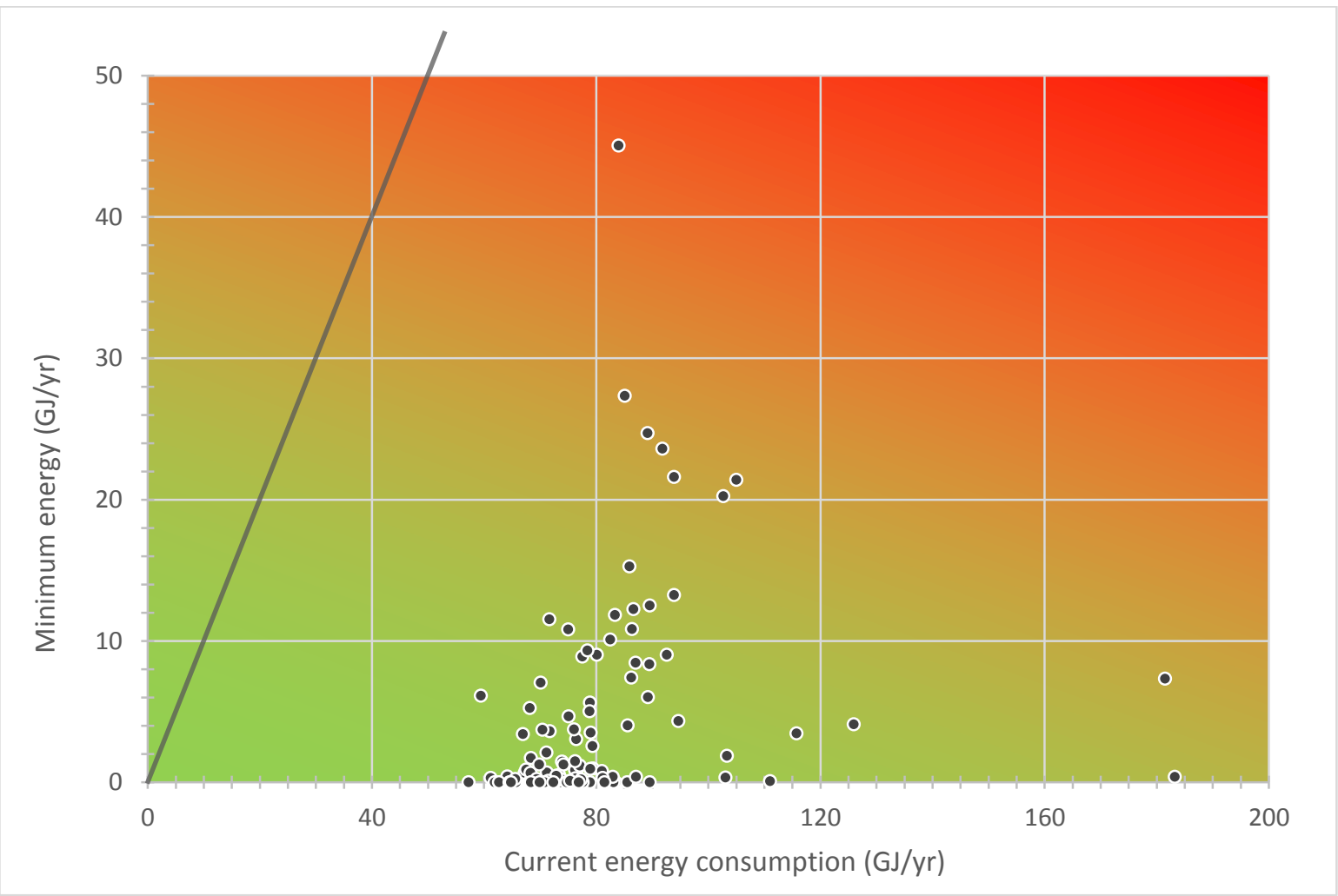


Figure 7. Christchurch maintainability space (2006), cost equal to ten percent of income shown

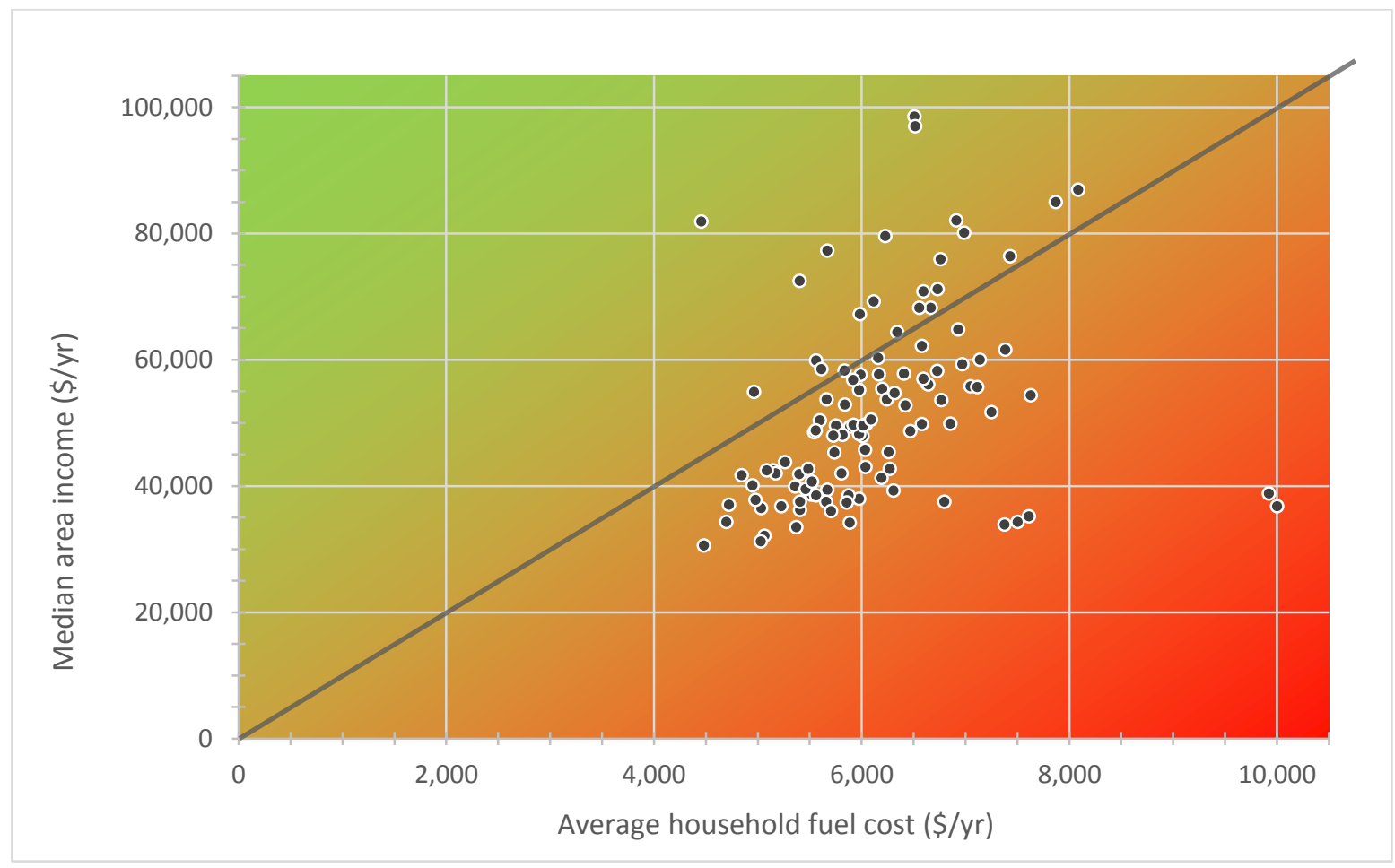

A comparative analysis of the VOILA outputs is presented in Figure 8. The output shows the interactions between adaptability and maintainability in areas, and provides some indication of the relative vulnerability compared to other areas. The lowest vulnerability areas are found $2-4 \mathrm{~km}$ to the north west of the CBD, where high accessibility provides adaptability and incomes are much greater than fuel costs. Other areas proximate to the CBD feature similar levels of adaptability, with lower levels of maintainability as incomes decrease relative to fuel costs. Outlying areas suffer from lower adaptability, although for many higher income areas this is offset by greater maintainability. Only three areas fall into the most vulnerable category of lowest maintainability and adaptability. These areas are all located on the eastern periphery of the city. Two types of area fall into the second highest vulnerability category, those with medium adaptability and low maintainability, and those with low adaptability and medium maintainability. Of the first group, most areas are located in a ring about the CBD, approximately $4 \mathrm{~km}$ out. Areas in the second group are scattered predominantly around the edges of the city. 
Figure 8. Comparative VOILA analysis of Christchurch

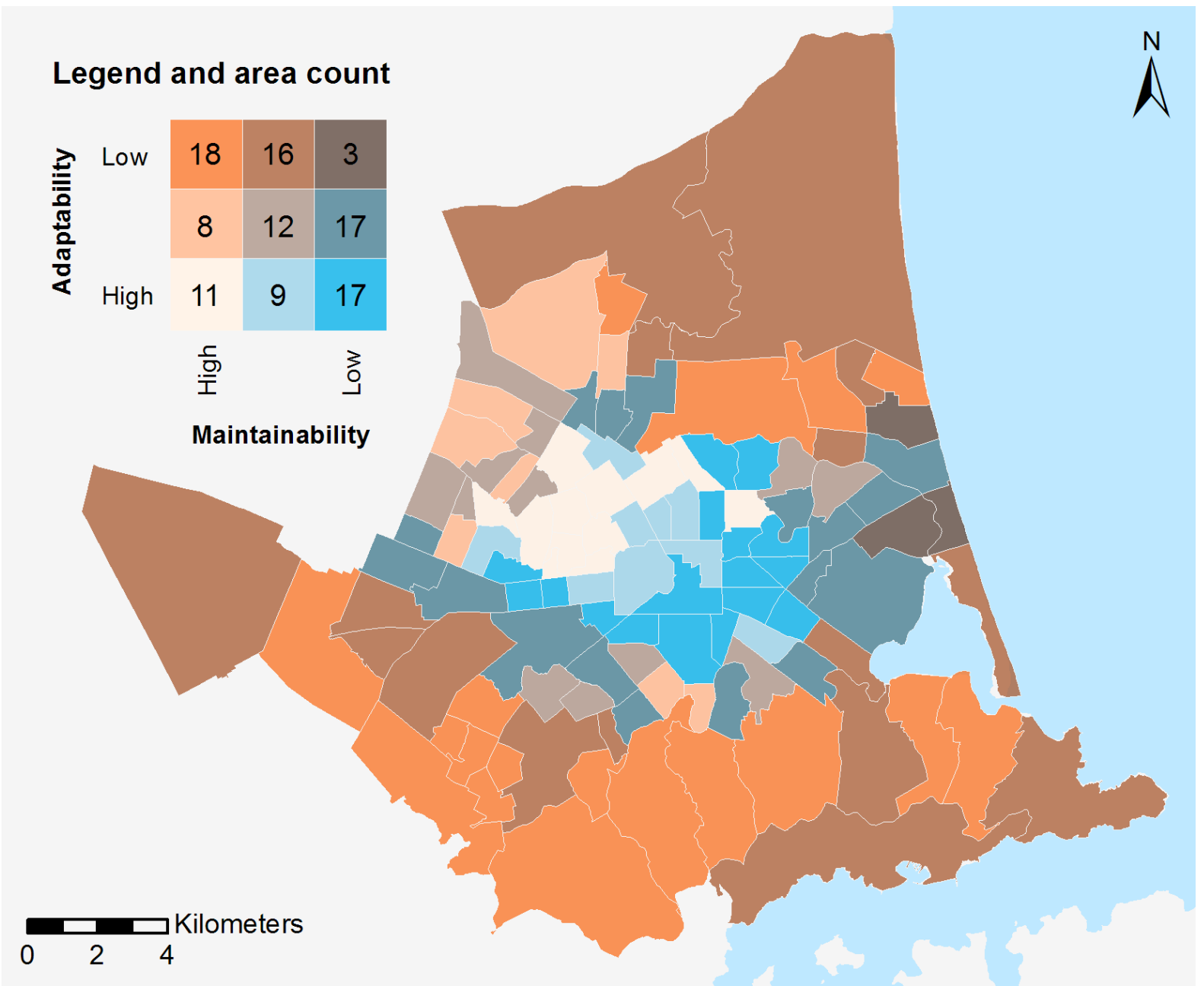

\section{Discussion}

The VOILA adaptability and maintainability spaces shown in Figures 6 and 7 indicate that high levels of adaptability for many Christchurch travellers will reduce vulnerability, although many areas are already considered to be in fuel poverty, spending more than $10 \%$ of their income on fuel. However, during fuel price rises it is likely that these travellers will be able to adapt.

The comparative analysis indicated a less linear pattern of vulnerability than was exhibited in earlier studies, such as VAMPIRE, of other cities. VOILA showed the outlying parts of Christchurch feature a number of higher-income areas where maintainability is high, despite lower adaptability. This is in contrast to other cities where the cheapest housing is typically seen on the fringes, attracting lower income residents. Comparatively, this indicates Christchurch may be less vulnerable to fuel shocks, as lower-income residents are nearer their activities, and are able to preserve access to their activities through adaptation. The analysis does indicate three areas in which both adaptability and maintainability are low; these are closely grouped, raising the possibility that targeted public transport improvements could be used to reduce vulnerability in these areas. The distribution of areas with medium adaptability and low maintainability, which form a ring about $4 \mathrm{~km}$ from the CBD, indicate that public transport and active mode network improvements may also assist residents in these areas. Fortunately most outlying 
areas in Christchurch are able to trade adaptability for maintainability, however this suggests that fringe developments attracting low income residents should be avoided, as the inherently low adaptability of these areas would leave travellers unable to maintain their travel particularly vulnerable.

\subsection{Model considerations}

If applying the method to cities with higher public transport ridership it would be necessary to include this cost in the calculation of transport costs. Developing a method for accounting for this, where specific data is unavailable, will be part of the future work for this research.

Compared to other oil vulnerability assessments the VOILA method is not as transferrable, given its reliance on area-level fuel consumption and cost data. To some extent this information may be available in other countries, for example, Li, Sipe, \& Dodson [24] calculated employment travel energy consumption using results of the Australian census, which collects employment destination information as well as mode of travel to work, and the registered vehicles database. The METAA characterisation can be applied to other areas, as it uses data that can be obtained from local government bodies, but it is computationally intensive.

\subsection{Future development}

It is intuitive that decreasing adaptability and maintainability will make travellers more vulnerable, but it is not currently known how these two variables combine or offset one another, nor the extent to which changes in either will quantitatively affect the ability of residents to endure oil shocks. Future work on the VOILA method will examine these aspects in greater detail and focus on developing a combined quantitative output.

Currently public transport costs are not included in the transport costs, due to limited availability. Future work will investigate this factor further, aiming to locate or develop a methodology for estimating public transport costs at the household or statistical unit level.

\section{Conclusions}

The Vulnerability to Oil: Income, Land-Use and Accessibility (VOILA) assessment developed by this research presents a valuable addition to the field of oil vulnerability. It combines spatial data of household transport energy consumption and fuel cost with a novel transport energy-accessibility metric, the METAA characterisation, to develop an improved oil vulnerability metric.

The nature of the input datasets means that variables can be directly assessed, without ranking or indexing, for example: current energy versus minimum energy. This means that different cities, areas within cities and areas in different cities can all be directly compared to one another. Most previous methods are able do only one of these, depending on the design of the metric. This also means that changes can be monitored over time. Where other studies might show that a particular area becomes less 
vulnerable relative to the other areas in the city over time, VOILA might show that the entire city is becoming more vulnerable, but the area is doing so at a slower rate.

Where other studies consider only work travel, VOILA assesses all purposes. This is important as shopping actually attracts a larger share of trips than employment, with social visits a close third, and travel to education might be considered as important as travel to employment for certain age groups. Employment is an important maintenance activity, but focusing solely on it ignores the requirement of humans to interact socially and engage in other maintenance activities.

VOILA reduces the use of proxies by clearly defining the problem: vulnerable areas are those that might lose access to activities during oil price rises as they can neither afford to spend more on fuel nor adapt their travel. Other studies included a variable of oil dependence, represented by various proxies, which typically assumed that travellers currently owning and using vehicles were dependent on oil. VOILA recognises that oil dependent areas are those in which greater amounts of oil are used and travellers are unable to adapt. Similar to previous studies, VOILA uses income to represent inability to pay more for fuel. This is due to a lack of alternative specifications and the complexity of fully defining this variable, which would have to account for many factors, including presence of dependents and mortgage or rental status, and would involve a large number assumptions.

VOILA is the first oil vulnerability study to include a comprehensive assessment of transport adaptation as a means of reducing the impacts of fuel price rises. Runting et al. [17] did consider the ability of travellers to offset price rises by walking or cycling to public transport. However, they do not consider what destinations might be accessible by the public transport service once accessed nor accessing activities by active modes. Combining the METAA characterisation with a fuel use database enables the adaptive capacity of areas to be quantified, and allows this key component of oil resilience to be assessed as part of the vulnerability analysis.

With the long term future of oil supplies uncertain it is imperative that planners and decision makers understand the implications that fuel price rises will have for urban travellers. This research presents an analytical method for quantitatively assessing the vulnerability of residents to oil price rises. The multifaceted approach of the analysis presents a better understanding of the underlying causes of vulnerability than previous studies, and is a step towards enabling more resilient communities. 


\section{Acknowledgments}

Research for this project was funded by the New Zealand National Institute of Water and Atmospherics (NIWA). The authors would also like to thank Abley Transportation Consultants for assistance, guidance and data during the development of the METAA model.

\section{Conflicts of Interest}

The authors declare no conflict of interest.

\section{References and Notes}

1. Greene, D. L. Transportation and Energy, Overview. In Encyclopedia of Energy; Cleveland, C. J., Ed.; Elsevier: Amsterdam, 2004; Vol. 6, pp. 179-188.

2. Grübler, A.; Nakićenović, N.; Schäfer, A. Dynamics of Transport and Energy Systems: History of Development and a Scenario for the Future; International Institute for Applied Systems Analysis: Laxenburg, Austria, 1993.

3. Newman, P.; Kenworthy, J. R. Sustainability and Cities: Overcoming Automobile Dependence; Island Press: Washington, D.C., 1999.

4. Aßmann, D.; Sieber, N. Transport in Developing Countries: Renewable Energy versus Energy Reduction? Transp. Rev. 2005, 25, 719-738.

5. Hall, P. The future of the metropolis and its form. Reg. Stud. 1997, 31, 211-220.

6. Frank, L. D.; Schmid, T. L.; Sallis, J. F.; Chapman, J.; Saelens, B. E. Linking objectively measured physical activity with objectively measured urban form. Am. J. Prev. Med. 2005, 28, 117-125.

7. Prevedouros, P. D.; Schofer, J. L. Trip Characteristics and Travel Patterns of Suburban Residents. Transp. Res. Rec. J. Transp. Res. Board 1991, 1328, 49-57.

8. Shaw, S.-L. Transportation and Land Use. In International Encyclopedia of Human Geography; Kitchin, R.; Thrift, N., Eds.; Elsevier: Oxford, 2009; pp. 470-475.

9. Newman, P.; Beatley, T.; Boyer, H. Resilient Cities: Responding to Peak Oil and Climate Change; Island Press: Washington, D.C., 2009.

10. Owens, S. E. Energy, Planning, and Urban Form; Pion: Distributed by Methuen (USA): London, 1986.

11. Benes, J.; Chauvet, M.; Kamenik, O.; Kumhof, M.; Laxton, D.; Mursula, S.; Selody, J. The Future of Oil: Geology versus Technology; International Monetary Fund, 2012; pp. 32-32.

12. Krumdieck, S.; Page, S.; Dantas, A. Urban form and long-term fuel supply decline: A method to investigate the peak oil risks to essential activities. Transp. Res. Part Policy Pract. 2010, 44, 306322.

13. Mohr, S. Projection of world fossil fuel production with supply and demand interactions. Doctor of Philosophy in Engineering, University of Newcastle: Newcastle, NSW, 2010.

14. De Almeida, P.; Silva, P. D. Timing and future consequences of the peak of oil production. Futures 2011, 43, 1044-1055.

15. Rickwood, P. The impact of rising oil prices on the transport sector. Aust. Plan. 2010, 47, 243-252.

16. Dodson, J.; Sipe, N. Oil Vulnerability in the Australian City: Assessing Socioeconomic Risks from Higher Urban Fuel Prices. Urban Stud. 2007, 44, 37-62.

17. Runting, R.; Corcoran, J.; Leung, A.; Pullar, D. Oil vulnerability: the effect of non-metropolitan areas and master planned estates in South East Queensland 2001-2006. Aust. Plan. 2011, 48, 117130. 
18. Dodson, J.; Sipe, N. Shocking the Suburbs: Urban Location, Homeownership and Oil Vulnerability in the Australian City. Hous. Stud. 2008, 23, 377-401.

19. Ice, K. VAMPIRE Analysis of Hillsborough County: A spatial representation of Oil and Mortgage Vulnerability. Master of Arts in Urban and Regional Planning, University of Florida: Gainesville, 2012.

20. Abley, S.; Krumdieck, S.; McDonald, G. New Zealand a future with less oil? A risk management study for Palmerston North; Abley Transportation Consultants: Christchurch, 2012.

21. Steele, W. E.; Gleeson, B. Mind the governance gap: oil vulnerability and urban resilience in Australian cities. Aust. Plan. 2010, 47, 302-310.

22. Arico, R. S. Measuring the oil vulnerability of Canadian cities. Master of Urban Studies, Urban Studies Program - Simon Fraser University, 2007.

23. Fishman, E.; Brennan, T. Oil Vulnerability in Melbourne; Institute for Sensible Transport: Melbourne, 2010.

24. Li, T.; Sipe, N.; Dodson, J. Investigating Private Motorised Travel and Vehicle Fleet Efficiency: Using New Data and Methods to Reveal Socio-Spatial Patterns in Brisbane, Australia. Geogr. Res. 2013, 51, 269-278.

25. Lovelace, R.; Philips, I. The "oil vulnerability" of commuter patterns: A case study from Yorkshire and the Humber, UK. Geoforum 2014, 51, 169-182.

26. Rendall, S. M. Minimum Energy Transport Adaptability. Doctor of Philosophy in Engineering, University of Canterbury: Christchurch, N.Z., 2012.

27. Krumdieck, S.; Page, S.; Watcharasukarn, M. Travel adaptive capacity assessment for particular geographic, demographic and activity cohorts; New Zealand Transport Agency: Wellington, 2012.

28. Rendall, S. M.; Page, S.; Reitsma, F.; Van Houten, E.; Krumdieck, S. Quantifying Transport Energy Resilience. Transp. Res. Rec. J. Transp. Res. Board 2011, 2242, 72-80.

29. Milne, A.; Rendall, S.; Abley, S. National travel profiles part B: Trips, trends and travel prediction; New Zealand Transport Agency: Wellington, 2011; p. 94.

30. Ministry of Transport (MoT) New Zealand Vehicle Fleet Statistics 2013.

(C) 2014 by the authors; licensee MDPI, Basel, Switzerland. This article is an open access article distributed under the terms and conditions of the Creative Commons Attribution license (http://creativecommons.org/licenses/by/3.0/). 